\title{
Preserving Natural Beauty
}

\author{
Writer: Melissa Cloutier* \\ Artist: Alyssa Ellis* \\ Photographer : Breanne Kshyk* \\ Grant MacEwan University, Canada
}

\begin{abstract}
This article pans into the world of art and considers its connection with nature by burrowing into Alyssa Ellis's painting, Tree Shadows, as well as explores the methods, tools, and process required in order for the painting to be created. Alyssa Ellis is a second-year student in Grant MacEwan University's Fine Arts Program with an instinctive passion for painting and nature. Learning of Ellis's search for and experience with painting nature, particularly trees, leads to a glimpse into her history of painting and with nature, which causes consideration for art as a portal capable of provoking environmental appreciation, compassion and conservation.
\end{abstract}

\section{Introducing The Project}

"You only conserve what you cherish, and the arts help us to cherish certain places," (Waters, as cited in Curtis, 2009, p. 182).

As summer merged with fall last year, and leaves began changing colours, Leslie Sharpe (Program Chair) led her ARTE 231 students on a plein-air painting fieldtrip to Whitemud Ravine Park where she instructed them to stay close to the trail and consider how to interpret a natural environment that is situated in an urban setting. This fieldtrip took place after the class had a lecture and slideshow about contemporary and traditional landscape painting practices. The students could choose to include urbanized aspects 
such as a path, stairs and garbage can in their interpretation, or to convey the very natural experience one can encounter in an urban park setting. Alyssa Ellis's impressionistic-rooted acrylic painting, Tree Shadows, was an outcome of this fieldtrip. This painting was carefully rendered over a two-week period and showcases the deeper, more natural parts of the park's environment.

Alyssa Ellis agreed to be interviewed about her Tree Shadows painting, and the creative process and research that the project involved. The journey to answer these questions unravelled the mystery of her artistic process and research, and revealed her instinctual nature.

\section{Experiencing for Research}

Once Ellis was on the Whitemud Ravine park trails, she chose to focus on what is natural beside the trail. After searching for approximately two hours, Ellis described coming across a naturally sloped area with a slight clearing where trees sparsely ran throughout. She spent two more hours in this place painting sketches, capturing photos, and absorbing this environment while she waited for the sun to begin setting so she could see light shining through the voids between the trees, bushes, and plants, and the shadow effects. Her sketches and photos would later be used, along with her memory of the experience, as foundations for the Tree Shadows painting and as a guide for its composition.

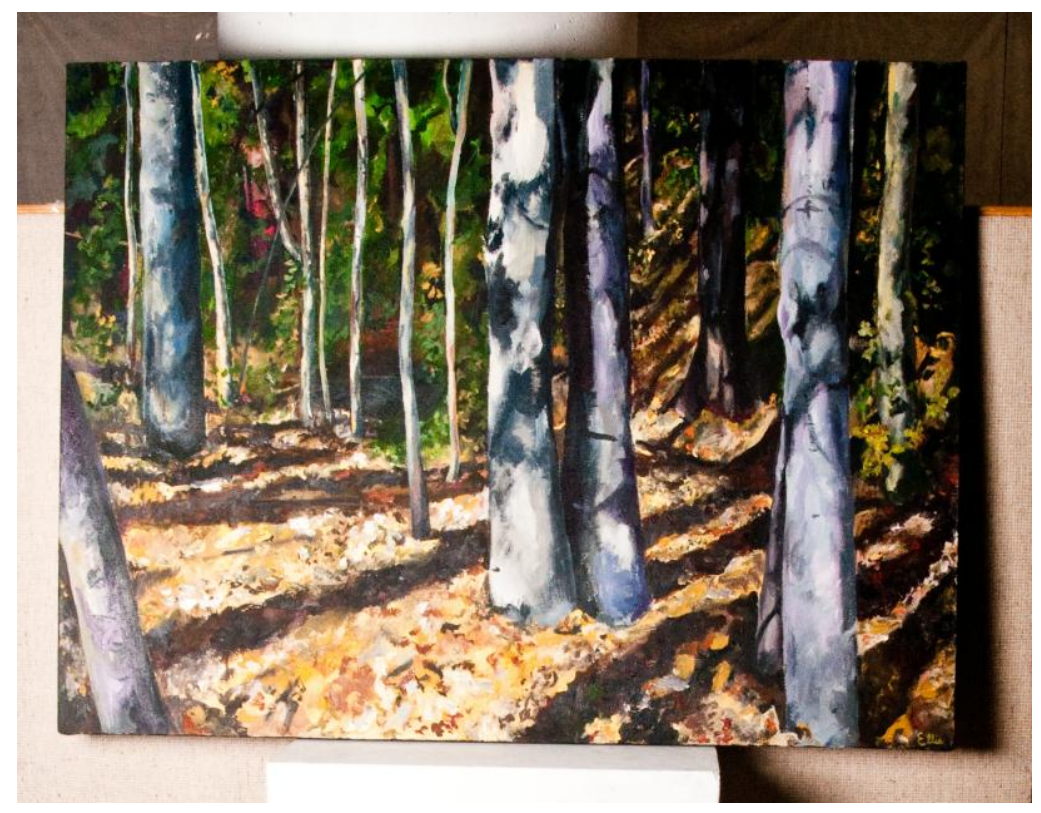

ECJ Volume 2, No. 1, 2012 


\section{Researching the Depiction}

"Composition is by nature," explained Ellis when asked about the placement of trees and other environmental aspects of her painting. The composition is the sole aspect of the environment that was exactly rendered within the painting. The slope of the terrain with a ditch area provoked Ellis to ponder if a creek had once flowed through the area. Weaving narratives for environments and naming beings and objects to encapsulate within Ellis's art is part of her creative process - she enjoys visualizing a story for her audience to interpret, and sharing the beauty of the natural world with those who wish to journey through this landscape of interpretation.

Ellis identified Monet's impressionistic works such as Water Lilies as a possible comparison to her artwork, especially when the following description of Monet's work is considered:

\footnotetext{
"The brushstrokes and the paint begin to assume an unprecedented prominence. As a result, instead of accepting a canvas as a convincing representation of reality, the viewer is forced to account of the technique and medium in experiencing the picture. This is consistent with Monet's recommendation that artists focus on a balanced paint scheme, form, and light of an object rather than its iconography. Monet emphasized the essence of a painted object as an abstract form and not as a replica of the thing itself," (Adams, 2002, p. 825).
}

That Tree Shadows is impressionistic-rooted becomes more clear when the previous quote is considered with this explanation of impressionism: "In their concern with political commentary, the Realists had emphasized social observation, while the Impressionists were concerned with the natural properties of light. They studied changes in light and color caused by weather conditions, times of day, and seasons, making shadows and reflections important features of their iconography," (Adams, 2002, p. 805).

Factors, such as paint choices and texture, were developed from memory and Ellis's interpretation of what she witnessed. When choosing colours to use within the painting, she followed her instinct and disregarded consistency. Instinctively, she used a full spectrum of balanced hues within the Tree Shadows. "Nothing is used straight from the tube," Ellis remarked. Paint colours were mixed based on personal attraction, a desire to use the full and balanced colour spectrum, what colours she felt should be present, and the artist's mood when the scene was considered. For instance, Tree Shadows has 
numerous and various darker and cooler tones, which reflects Ellis's being alone during her experience in the environment, as well as reflects the influence that the time periods imposed when she painted - typically during the hours of ten and two p.m.

The type of acrylic used also affects colour outcomes. Ellis prefers acrylics because she feels they offer better pigments and the acrylics cover a canvas easier. She also explained that she has often blended colours on canvas because experimenting in this way can result in unique shades, making the process more enjoyable. She estimated using about six different types of coloured paint tubes, including primary colours red, yellow, and blue, as well as bold purples and greens. No mediums were used during this painting process. Ellis noted that painting with acrylics is all about blending and layering. Typically, Ellis uses varying sizes of filbert brushes and a very small round brush - her preferred brush must be durable and of high quality.

The three by four feet canvas was personally assembled by Ellis using pinewood, then stretched and primed with gesso prior to painting. When asked about whether or not she takes environmentally-friendly approaches when using painting products, Ellis responded, "Unfortunately the paints can be harmful to the environment but only if they are dumped into natural areas. The key to help keeping these products out of the environment is to not waste. I try to use everything on my palette so nothing goes into the garbage or is washed down the drain."

Ellis described the painting process she applied as beginning with under-painting to block out the painting. Then wet onto wet, drybrushing and impasto techniques were used interchangeably everywhere. Texture, especially the bark, within the painting was created by drybrushing.

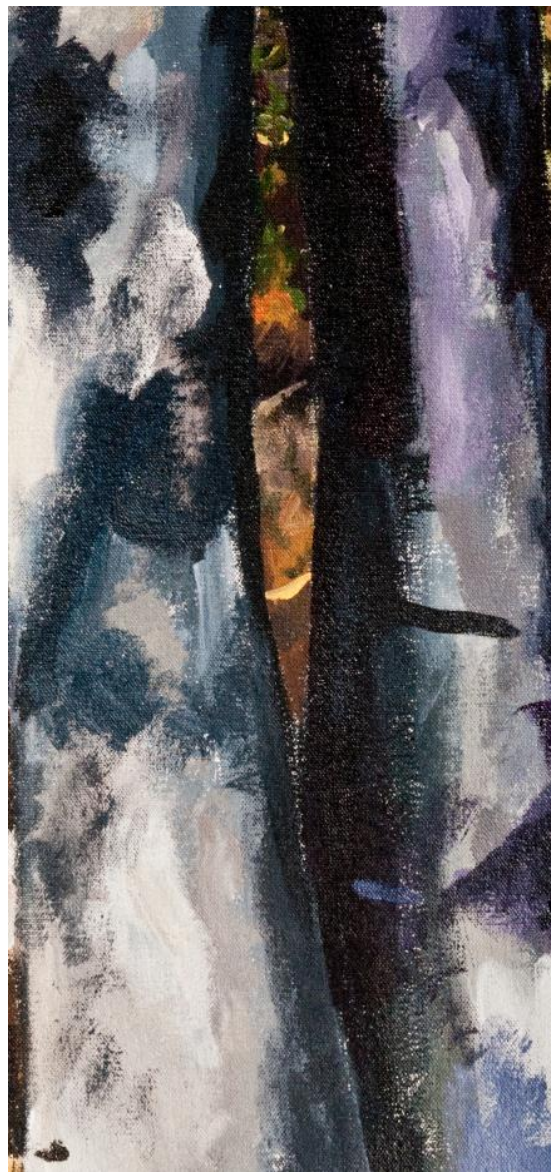
Ellis's targeted brush strokes, which are "sporadic..., loose but still soft, and not overbearing," were a primary important element in her painting because of the depth and texture that brush strokes add.

In Tree Shadows, highlights draw the eye towards a brighter red area to create a focal point for consideration. This red in the background behind the trees within the 


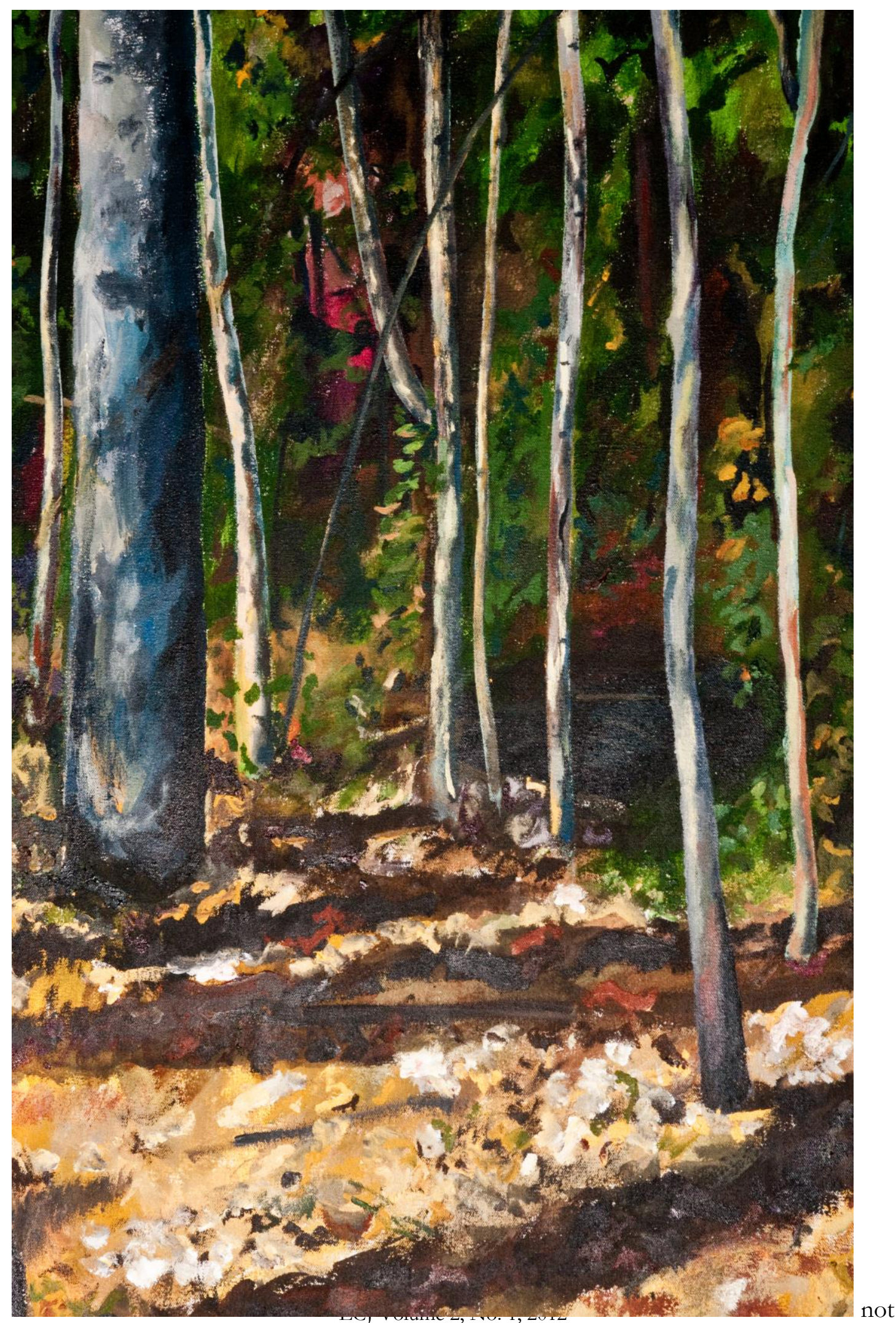


painting was not originally present while at the ravine. Even the artist is not sure why she added this colour, yet the mysterious colour seems to provoke consideration- why is the red there and what does it indicate? This use of red arouses a narrative within the painting, along with other factors like the ditch and (or) dwelling that Ellis incorporated because it makes her audience consider elements in the painting on a deeper level in that the elements cause questioning around their purposes. When asked if her painting had been motivated by factors other than the Whitemud Ravine Park, Ellis identified Chiara Fersini as an Italian photographer whose shadowing techniques had inspired her.

When looking for inspiration for painting, Ellis explores photography sites with pictures of trees, yet prefers to see them firsthand if she can to add to her experience, or the feeling and mood of seeing the scene. Hence, Ellis prefers to do primary research. Her deep absorption and instinctual encapsulation of her environment indicate her appreciation of and connection with the natural environment.

\section{Studying The Artist}

Ellis explained she feels like she's on a journey in which she is unsure where she is going. Currently, this journey has brought the twenty-year-old Edmonton-native to Grant MacEwan University, where she is a second-year student in the Bachelor of Fine Arts program with plans to further her education. In two years, Ellis estimated completing about 60 projects that varied in types of art. An inquiry as to why she chose Grant MacEwan University for her studies resulted in the following response:

I chose to take fine arts when I realized art is a language used worldwide. To me it is no different than taking French or Russian. I chose Grant Macewan University for the boot camp qualities and standards they... [impose] upon their students. They are strict and hard but I figured if I could get through this, I could get through anything. 


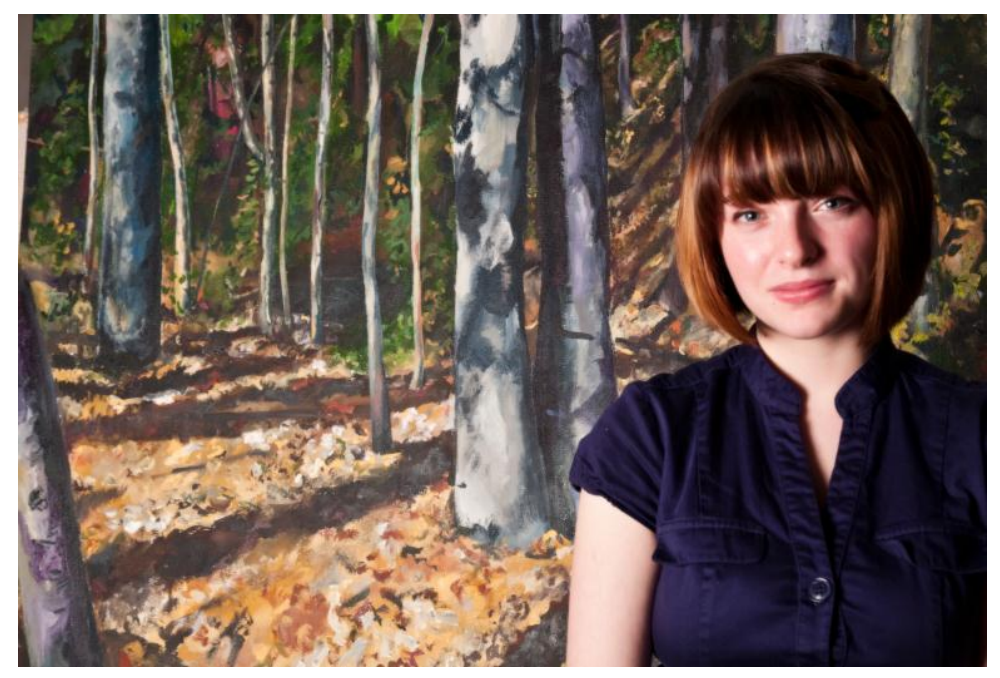

Ellis has been painting ever since childhood. Acrylic is her forte but she has experimented with many different media. Birds are often her inspiration along with nature photos. She has always been around nature - in scouts, always outside, camping, and hiking with her family. This is why she described being in nature as feeling like home because she experienced it so much in her youth.

Trees in particular give her the feeling of home. She explained every tree is different and every tree has a different bark, like a fingerprint. She admires that many trees have unique uses, (for instance, healing, materials and climbing). She shared that she has a bucket list of trees that she desires to see personally and photograph throughout her life. The eucalyptus deglupta in the Philippines is a type that she particularly wishes to paint. Ellis plans to continue capturing trees for many reasons, including their beautyespecially bark and texture attract her - their various colourings, and their capabilities.

\section{Art Provoking Conservation}

When asked how she felt about nature and why it became a focus in her artwork, Ellis explained, "Everything goes back to nature. Everything is connected. If we don't have nature we're breaking that connection. When I think about it, I think about when I die. And I don't have a religion so I feel like when I die I'm going to be put into the earth and it will accept me. So I want to honour it because everything goes back to nature."

Her appreciation for nature, as well as her recognition of its relatedness to us, reminisces another quote: "...if we are going to have a new connection to the environment it will have to happen in individual hearts and souls...the artist can help us fall in love with the earth again," (Berensohn 2002). Ellis's art, particularly the Tree Shadows painting, encourages its audience to pause and appreciate what often goes unappreciated. Ellis is an example of how art that revolves 
around nature eternalizes environment and provokes a desire to keep what is unquestionably beautiful and precious. Most importantly, Ellis achieves what Bill O’Toole (as cited in Blackwell Publishing Limited, 2007, p. 178) explains perfectly: “... The arts provide a different way of viewing the same thing ... they can turn what is a swamp full of mosquitos and snakes into something that should be saved because it is so beautiful." This is a means of speaking for the earth. Ellis aims to share what she recognizes as beauty and to eternalize this beauty for her audience's interpretation. Hence, the need to share can conjure connection and suggest a need for conservation.

*Writer: Melissa Cloutier is a fourth year student in the Bachelor of Applied Communications in Professional Writing program. She has a passion for writing and the environment.

* Artist: Alyssa Ellis is a graduate of the Fine Arts program at Grant MacEwan University, Canada.

*Photographer: Breanne Kshyle is a Design Studies student at Grant MacEwan University, Canada. Her studies focus on photography.

\section{References}

Adams, L. S. (2002). Art Across Time (2 ${ }^{\text {nd }}$ ed.). New York: The McGraw-Hill Companies, Inc.

Chiara Fersini (n.d.). http://www.himitsuhana.com/

Curtis, D. J. (2009). Creating inspiration: The role of the arts in creating empathy for ecological restoration. Ecological Management \& Restoration, 10(3), 174-184.

Blackwell Publishing Limited (2007). Promoting Conservation through the Arts: Outreach for Hearts and Minds. Conservation Biology, 21(1), 7-10. 